\title{
O VAZIO DE REMIGIA
}

THE EMPTINESS OF REMIGIA

Andre Rezende Benatti ${ }^{1}$

RESUMO: o artigo tem como objetivo analisar a narrativa "Ña Remigia", de Josefina Plá, escritora, artista plástica, historiadora, jornalista, dramaturga, ensaísta, catedrática, critica de arte e de literatura de origem espanhola e naturalizada paraguaia. As bases analíticas do conto de Josefina Plá giram em torno das teorias da narrativa, de gênero, da violência e da tragicidade. Interessa-nos o modo como que esse feminino, envolvido pelo trágico e pelo violento, foi construído no texto de Josefina Plá, em uma relação de interdependência das microestruturas.

PALAVRAS-CHAVE: Josefina Plá; Conto; Violência; Tragicidade; Feminino.

ABSTRACT: This present article has as its objective to analyze the "Ña Remigia" tale by the spanish and naturalized paraguayan writer, plastic artist, historian, journalist, playwright, professor, art and literature critical Josefina Plá. The underpinnings of the Josefina's tale are around the theories of narrative, gender, violence and tragedy. We are interested in how this female engaged by tragic and violent were built on Josefina's text, in a relation of interdependence of microstructures.

KEYWORDS: Josefina Plá; Tale; Violence; tragedy; Male.

...Estás lejos me dice Y debieras estarlo ya que el tiempo es distancia para la piel marchita y la distancia es tiempo para los pies cansados Josefina Plá (1996-B)

\section{Palavras Iniciais}

Um romance conta uma estória ${ }^{2}$ e sem ela não há romance, averba Forster em Aspectos do Romance (2004). Essa afirmação pode ser aplicada a outro tipo de narrativa

\footnotetext{
${ }^{1}$ Doutorando em Letras Neolatinas: estudos literários hispânicos, pela Universidade Federal do Rio de Janeiro; Professor de Literatura Espanhola, na Universidade Estadual de Mato Grosso do Sul UEMS/Campo Grande. E-mail: andre_benatti29@hotmail.com
} 
literária, o conto, este que narra algo inventado, ainda que pareça realidade, como ocorre no conto Ña Remigia, de Josefina Plá, publicado na coletânea La Pierna de Severina, em 1983. Neles temos exposta a "vida" de uma senhora já em idade avançada. Por se tratar de uma narrativa, o conto narra a vida, em um tempo, tempo este localizado em determinado espaço, e quem conta os fatos é um ser entendido por Forster (2004) como uma "massa verbal" que é parte do autor. Remigia nunca será uma pessoa real, pois a função do escritor é escrever o que estaria oculto na vida de determinada personagem, tornando-a literária, mesmo que haja um fundo histórico em sua construção. Sobre as personagens da "vida real" não se pode saber tudo e é isso o que as difere das personagens ficcionais, uma vez que destas últimas é possível saber tudo o que se pode saber de alguém, aguçando nosso poder de leitor.

$\mathrm{Na}$ literatura há a criação de todo um sistema social específico, no qual as ações se passam em um tempo construído / criado a partir, normalmente, de fatores externos, sociais. Esses fatores desempenham um importante papel na estruturação da obra literária.

A sociedade existe antes da obra, porque o escritor está condicionado por ela, reflete-a, exprime-a, procura transformá-la; existe na obra, na qual nos deparamos com seu rastro e sua descrição; existe depois da obra, porque há uma sociologia da leitura, do público, que, ele também, promove a literatura, dos estudos estatísticos à teoria da recepção. (TADIÉ, 1992, p.163).

No entanto, na obra de arte literária há uma sociedade que não é e nunca será a mesma sociedade que existe fora dela, pois, se há um objetivo da literatura, este não é retratar a realidade empírica, e mesmo que o fosse não haveria meios para que se conseguisse com sucesso tal objetivo. O que há na obra literária é a construção de um novo mundo, capaz de refletir parcial e opacamente a sociedade externa, porém seguindo seus próprios padrões e estruturas narrativas. É nesse mundo que nos atemos para analisar o conto de Ña Remigia.

\footnotetext{
${ }^{2}$ Nomenclatura adotada por Edward Morgan Forster, em Aspectos do Romance, ao se referir ao que conta uma narrativa.
} 
[...] a criação literária é uma coisa diferente da realidade, mas também significa o aparentemente contrário, ou seja, que a realidade é o material da criação literária. Pois é apenas aparente esta contradição, já que a ficção só é de espécie diversa da realidade por que esta é o material daquela. (HAMBURGUER, 1986, p. 2).

Por tratar de um mundo construído a partir do exterior, do social, o mundo da obra literária trata de assuntos pertinentes ao meio no qual teve sua origem. O que se encontra no texto (aqui nos referimos especificamente às personagens e às suas atitudes) é ou pretende ser, de acordo com Forster (2004), humano. Portanto, vemos o texto literário como um fenômeno criado pela mão do homem com o substrato oferecido pela realidade empírica.

Do ponto de vista social, e por agora nos remetemos a Marisa Lajolo (2001), a obra literária é um objeto social muito específico, capaz de fazer o ser humano refletir sobre si mesmo, vendo-se como representação social. Os sofrimentos e as desventuras da pequena Maria no conto Siesta, quem também está presente em La Pierna de Severina ${ }^{3}$, por exemplo, bem como os de Severina e de Sisé em suas respectivas narrativas, são de um chamamento extremamente vigoroso. A própria Josefina Plá afirma na introdução de sua coletânea que o que ela escreve em seus contos não é apenas de caráter local, tipicamente do Paraguai, mas algo que poderia acontecer em qualquer parte do mundo, expandindo os limites de seus textos.

Estoy convencida de que todos ellos, aunque rebotes de vivencias locales, son universales en su humana raíz. Cambiando nombres, paisajes y tal cual circunstancia, pueden darse, se dan, en cualquier otra parte del mundo. ${ }^{4}$ (PLÁ, 1996-A, p. 163).

Suas mulheres são mulheres do cotidiano, vivendo situações aparentemente comuns, sendo negados a elas alguns direitos humanos básicos, não sendo vistas, nem ouvidas, silenciadas que são pela hipocrisia que as abraça sufocantemente. Plá instaura a feminilidade nessas mulheres, (con)formadas textualmente pelas microestruturas textuais.

\footnotetext{
${ }^{3}$ As referências a outros contos são narrativas também presentes na coletânea de textos La Pierna de Severina.

${ }^{4}$ Trad. nossa: "Estou convicta de que todos eles, ainda que retomados de vivências locais, são universais em sua raiz humana. Mudando nomes, paisagens e algumas circunstâncias, podem acontecer em qualquer outra parte do mundo."
} 
As personagens, de acordo com Candido (2002), são seres fictícios, isto é, têm uma concepção fantasiosa que cria a impressão da mais legítima verdade existencial, numa condição de mímesis como exposta por Aristóteles em sua Poética (2000). Se estabelece uma relação entre o ser vivente (o autor) e o universo fictício (a obra) que se concretiza por meio da personagem. Entre o "ser vivente" e o "universo ficcional" há tanto diferenças como afinidades e ambas são importantes para a criação do sentido de verdade na obra, a verossimilhança. Para que isso aconteça, é preciso a investigação sobre as condições de existência da personagem, começando por descrever, do modo mais empírico quanto possível, a nossa percepção de personagem. Neste texto analisaremos as questões relativas à personagem Remigia, do conto Na Remigia.

\section{Eu desejo a solidão}

O conto Na Remigia narra a história da personagem título, Remigia, mulher de setenta e cinco anos que ao sofrer um acidente vascular cerebral que deixa parte de seu corpo paralisado é abandonada num hospital por seus parentes. A estruturação começa por esse estado de abandono e assim são apresentadas as personagens e as peripécias de Remigia, em um diálogo que ela tem com a mulher de um médico a quem conhece há quarenta anos e que a visita como uma demonstração de amizade. Remigia conta sua vida à "amiga" várias vezes. No entanto, já velha e no final da vida, não aceita sua situação e sempre repete a mesma toada. "- Lo que yo quiero saber, si me voy a curar." (PLÁ, 1996-A, p. 203); “- Yo quiero irme a mi casa. Allí solamente me voy a curar.”6 (PLÁ, 1996-A p.203).

Toda a história de Remigia é contada por um narrador personagem, em meio aos diálogos da protagonista da história, que já havia contado sua trajetória à narradora, a mulher do médico, que também presenciara alguns dos fatos. O narrador-testemunha, como é o que acontece no conto Ña Remigia, é caracterizado de acordo com a classificação de Friedman, citado por Leite:

\footnotetext{
5 Tradução nossa. "O que eu quero saber é se vou me curar."

${ }^{6}$ Tradução nossa. "Eu quero ir para minha casa. Somente ali vou me curar."
} 
Ele narra em 1.a pessoa, mas é um "eu" já interno à narrativa, que vive os acontecimentos aí descritos como personagem secundária que pode observar, desde dentro, os acontecimentos, e, portanto, dá-los ao leitor de modo mais direto, mais verossímil. Testemunha, não é à toa esse nome: apela-se para o testemunho de alguém, quando se está em busca da verdade ou querendo fazer algo parecer como tal.

No caso do "eu" como testemunha, o ângulo de visão é, necessariamente, mais limitado. Como personagem secundária, ele narra da periferia dos acontecimentos, não consegue saber o que se passa na cabeça dos outros, apenas pode inferir, lançar hipóteses, servindo-se também de informações, de coisas que viu ou ouviu, e, até mesmo, de cartas ou outros documentos secretos que tenham ido cair em suas mãos. (1994, p. 37-38)

Todas as informações a respeito da Remigia nos são transmitidas pela voz da mulher do médico, que presenciou ou ouviu as histórias de sua vida.

(No estoy mintiendo para consolarla. Muchas hemiplegias regresan. Ella misma acaso no quedó con el brazo derecho colgante, muerto, a la par de la pierna?... Ahora lo mueve bien. Lo ha recuperado. ¿Por qué no recuperará también la pierna poco a poco?... Hace solamente tres meses del ataque. Pero Remigia siempre fue impaciente. Nunca quiso depender de los demás. Le gustó siempre vivir sola). ${ }^{7}$ (PLÁ, 1996-A, p. 203)

Ao lermos o conto, percebemos que todo o universo que envolve a personalidade e a vida da personagem título são marcas cruciais para a caracterização do universo feminino e tudo o que cerca: o tempo e o espaço em que a história está sendo contada se faz de forma memorialista, forma esta que é uma marca do feminino.

Castello Branco (1991) discorre sobre a afirmação de alguns teóricos sobre a relação do feminino com a memória, que se dá pelo fato de que, historicamente, as mulheres ficaram confinadas em suas casas sem contato com o mundo externo. Elas teriam, então, encontrado na escrita memorialista uma maneira de expressar seus sentimentos em relação à vida.

\footnotetext{
7 Tradução nossa: "Não estou mentindo para consolá-la. Muitas paralisias regressam. Ela mesma acaso não ficou com o braço direito pendente, morto, o par de pernas?... Agora o move bem. Recuperou-o. Por que não recuperará também a perna pouco a pouco?... Faz somente três meses do ataque. Mas Remigia sempre foi impaciente. Nunca quis depender dos demais. Sempre gostou de viver sozinha."
} 
[...] quem sabe, a mulher tenha preferido escrever memórias não tanto porque as memórias the convenham pelo que elas têm a dizer, mas, sobretudo pelo modo com que elas dizem o que têm a dizer. Talvez essa escolha se deva, portanto, a uma preferência por formas discursivas que se aproximam que se assemelham. (CASTELLO BRANCO, 1991, p, 30).

Para a autora, muito dessa relação entre o feminino e a memória ocorre pela nostalgia emanada, por ambos, na busca de um retorno ao passado para efetuar um resgate do que já foi vivido. No entanto, esse processo memorialístico não deve ser visto como uma busca de algo que preencherá uma lacuna e sim "[...] a própria lacuna, enquanto perda, rasura e decomposição da imagem" (CASTELLO BRANCO. 1991, p. 32). Dessa forma, tal dispositivo acaba por revelar seu caráter rasurado nesse processo de tentativa de resgatar o que já foi vivido da mesma maneira (ou como teria sido) como o foi no passado.

Esse resgate do vivido pode ser percebido no decorrer de todo o conto $\tilde{N} a$ Remigia. Nele a protagonista, para além de querer o retorno de sua vida passada, deseja acima de tudo sua solidão, esta que ela acalentou por toda a sua vida, a solidão de sua casa, das paredes (LACAN, 2011) que protegem sua vida, a partir ela já não tem mais o poder de voltar sozinha para sua solidão, acaba por se violentar.

A violência, que Hannah Arendt (2011) esclarece ser a ausência da autoridade e que por conta dessa ausência se exacerba no que há de mais instintivo no homem, desde os primórdios da história humana tem se feito presente. Podemos até dizer que grande parte da evolução da raça humana se deu por meio das violências cometidas pelo homem. De acordo com Arendt, a

[...] agressividade, definida como um impulso instintivo, diz-se que ela representa o mesmo papel funcional, no âmbito da natureza, que os instintos sexuais e os de nutrição do processo vital do indivíduo e da espécie. Mas diferentemente desses instintos, que, por um lado, são ativados por necessidades corporais prementes, e, por outro, por estímulos externos, os instintos agressivos no reino animal parecem ser independentes de tal provocação; ao contrário, a falta de provocação conduz aparentemente à frustração do instinto, ao 'recalque' da agressividade, que de acordo com alguns psicólogos, causa o bloqueio da 'energia' cuja conseqüente explosão será extremamente perigosa. [...] Segundo essa interpretação, a violência sem provocação é 'natural'; se ela perdeu sua rationale, basicamente, a sua função na autopreservação, 
tornou-se 'irracional', e essa é supostamente a razão pela qual os homens podem ser mais 'bestiais' do que outros animais. (2011, p. 79).

São homens que, confusos em relação ao que os cerca, buscam em sua própria natureza uma explicação para sua agressividade, no entanto, fazendo isso, acabam, por conta de sua racionalidade, tornando-se irracionais, mais selvagens que outros animais. Portanto, não é surpresa que a literatura pense sobre a violência e sobre a agressividade humana das mais diversas maneiras, expondo cruamente a violência humana, como em Na Remigia, quando esta, Remigia, deseja a solidão de sua própria casa, agredindo a si mesma, não querendo a companhia de outros.

Bachelard (2008) considera a casa como o nosso primeiro universo. A casa é o abrigo primordial do homem; ela o acolhe e o faz sonhar; na casa ele pode desfrutar a solidão. Para o autor, se estudarmos fenomenologicamente os verdadeiros pontos de partida da imagem, serão revelados concretamente os valores do espaço habitado, o nãoeu que protege o eu, ou seja, a casa que protege o humano.

\begin{abstract}
Nosso objetivo está claro agora: pretendemos mostrar que a casa é uma das maiores (forças) de integração para os pensamentos, as lembranças e os sonhos do homem. Nessa integração o principio de ligação é o devaneio. O passado o presente e o futuro dão a casa dinamismos diferentes, dinamismos que não raro interferem, às vezes se opondo, às vezes excitando-se mutuamente. (BACHELARD, 2008, p.26).
\end{abstract}

Remigia quer a todo custo voltar à sua casa, seu lugar de segurança, seu refúgio contra o mundo exterior, como se a casa a curasse de todos os males, como se a solidão Ihe fosse o melhor remédio. "- Quiero irme a mi casa. ¿Por qué no me dejan? Aquí no me hallo. [...] - Yo siempre me cuidé sola, nunca nadie me cuidó. Nunca me hizo falta nadie. [...]- Quiero irme a mi casa." (PLÁ, 1996-A, p. 213).

As paredes de solidão que Remigia procura e que construiu em sua vida, por sua condição feminina, na busca de proteção e de libertação das amarras às quais está condicionada pelo feminino podem ser caracterizadas como uma violência contra o seu próprio ser. De acordo com Benjamin, citado por Seligmann-Silva (2005, p. 23), “[...]

\footnotetext{
${ }^{8}$ Tradução nossa: " - Quero ir para minha casa. Por que não me deixam? Aqui não me acho. [...] - Eu sempre me cuidei sozinha, nunca ninguém me cuidou. Nunca me fez falta ninguém. [...] - Quero ir para minha casa."
} 
nunca existiu documento da cultura que não fosse ao mesmo tempo um [documento] da barbárie". Portanto, confirmamos que a forma com que a sociedade ocidental vem conduzindo suas relações de gênero ao longo do tempo tornou-se cultural, configurandose como um ato de violência, nesse caso, contra o feminino.

Se a memória, como o sonho, possui o seu umbigo, o seu ponto cego em que tudo nada cabe, como uma absurda valise cujo fundo se perdeu, mas cujos objetos (para sempre perdidos) continuam lá, os textos da memória, mais ou menos oficiais, mais ou menos crédulos de uma verdade íntegra e de referencialidade possível, mergulharão sempre nesse buraco negro, nesse inominável do discurso, nesse silêncio de palavras que se abrem sobre o vazio. [...]. (CASTELLO BRANCO, 1994, p. 61).

Indomável também é Remigia quando se abre para o vazio, para seu próprio silêncio a ponto de não conseguir suportar seu próprio estado pelo desejo de viver em suas paredes de memórias, sua casa, lugar onde a solidão the faz a mais eficaz companhia, lugar onde ela pode viver com $\backslash$ como ela mesma.

A maneira com que a autora constrói a personagem faz com que ela seja irredutível em suas concepções, em seu desejo pela solidão. De acordo com as nomenclaturas de Forster (2004), podemos perceber que Remigia é uma personagem plana: "Na sua forma mais pura, são construídos ao redor de uma idéia ou qualidade simples; quando neles há mais do que um fator apreendemos o início de uma curva na direção dos redondos." (FORSTER, 2004, p. 85). A ideia central que percebemos na narrativa é a fixidez do pensamento de Remigia, que em sua casa, dentro de suas paredes, estará segura do mundo. "- Yo quiero irme a mi casa. Allí solamente me voy a curar. Siempre me enfermava y me curava sola." ${ }^{9}$ (PLÁ, 1996-A, p. 203).

Percebemos também que a partir dessa ideia de que a personagem plana possui uma característica fixa vemos que ela tem como fixidez a construção do feminino dada por Lacan em Estou falando com as paredes (2011). Com a criação e o amparo das paredes que impedem a chegada de uma "dominação", o sujeito se protege do vazio, vazio este em que o feminino se faz e que constitui sua essência.

\footnotetext{
${ }^{9}$ Tradução nossa: "Eu quero ir para minha casa. Somente lá vou me curar. Sempre adoecia e me curava sozinha."
} 
É esta solidão entre paredes que Remigia buscou sua vida toda. Percebemos tal atitude da personagem como uma forma de suprir a ausência da mãe, que morre quando ela tem apenas seis anos e passa a morar com as irmãs mais velhas, casadas e com filhos. Remigia precisa dividir a atenção de suas irmãs com os filhos delas. Pela necessidade de um espaço onde pudesse se desenvolver, manter suas memórias, manter-se a salvo do mundo exterior, esconde-se embaixo da cama de sua irmã. Esse é seu primeiro espaço solitário, a primeira parede que ela consegue erguer.

[...] Al principio todo había ido bien; pero no tardó en enturbiarse el horizonte. Remigia se prendía a las polleras de la hermana mayor como antes a las de la madre; pero desgraciadamente acá tenía competidores con derechos de primo ${ }^{10}$ ocupante; y como el primogénito era varón, resultaba Remigia siempre con arañazos en las mejillas o un ojo morado. Entonces dio en pasarse la vida bajo la cama del matrimonio. De allí no salía, de día al menos, mientras no se llamaba con la mamadera, con gran escándalo de sus sobrinos coetáneos que no entendía la razón del privilegio). [...] Remigia, que se sentía protegida por la voluntad todopoderosa de Doña Ceferina hasta después de difunta ésta [.... ${ }^{11}$ (PLÁ, 1996-A, p. 205).

A partir desse ponto, sua vida passa a ser regida, por vontade dela mesma, pela solidão como forma de preservação de si própria, tendo como proteção sua própria memória.

\begin{abstract}
Uma coisa é sair 'reformulado' de uma experiência dolorosa, outra é continuar como espectador de um mundo e de uma injustiça que se não se aceita e se denuncia, encarnando uma verdade à custa de um exílio em si próprio. Essa exigência ética não deixa de lembrar a figura de Antígona. Antígona entra em rebelião para que se fala justiça ao seu irmão; reclama para ele uma sepultura decente. Não privilegia um lei sobre outra. Como um ser irreconciliado com o grupo, ela encarna o desejo de tornar-se, pela sua morte, a memória insuportável desse conflito. A ética da revolta é a de uma resistência que denuncia o impasse para onde conduz a lei dominante. Em um mundo como o nosso como esquecer que estamos,
\end{abstract}

\footnotetext{
${ }^{10}$ Grifo da autora.

${ }^{11}$ Tradução nossa: "[...] A princípio tudo havia ido bem; mas não demorou em turvar-se o horizonte. Remigia se agarrava às saias da irmã mais velha como antes às da mãe; mas desgraçadamente aqui tinha competidores com direitos de primeiros ocupantes; e como o primogênito era varão, resultava Remigia sempre com aranhões nas bochechas ou um olho roxo. Então deu de passar a vida debaixo da cama do casal. Dali não saia, de dia ao menos, enquanto não lhe chamavam com a mamadeira, com grande escândalo de seus sobrinhos coetâneos que não entendiam a razão do privilégio. [...] Remigia, que se sentia protegida por vontade todo poderosa de Dona Ceferina até depois de defunta esta [...].”
} 
ainda hoje, entre a barbárie, a violação das sepulturas e a ilusão de um mundo melhor? (MANNONI, 1999, p.27).

No decorrer da vida, Remigia tenta apreender o passado dentro de suas memórias, dentro de sua casa protetora. É o passado que ilude Remigia a uma cura para todos os seus males. A dor presente em sua vida é amenizada em sua casa e sempre retorna à expressão mais célebre de toda a narrativa, a que mais retrata Remigia "- Yo quiero irme a mi casa. Allí solamente me voy a curar. Siempre me enfermava y me curava sola."12 (PLÁ, 1996-A, p. 203).

Os fatos decorrentes da construção da vida de Remigia a encerram em seu universo feminino. Nesse mesmo universo, temos a percepção dos efeitos trágicos na vida da personagem. Szondi (2004), ao citar Scheler, aponta o conflito trágico como o aniquilamento pelo que seria a salvação. A solidão de Remigia em sua casa, que para ela seria sua salvação, passa a ser seu aniquilamento com sua velhice. Portanto, podemos fazer uma ponte entre o feminino e o trágico dentro da narrativa de $\tilde{N} a$ Remigia: as paredes de criação do feminino, como definidas por Lacan (2011), que poderiam ser a salvação, no conto tornam-se a derrocada da personagem, que se encontra sozinha há três meses em uma cama de hospital.

Em meio à tragédia da vida de Remigia, vê-se a narradora, mulher do médico, como um grande fator humano no conto, pois mesmo sem ser parte da família de Remigia permanece a seu lado, talvez como uma forma de consolo.

Por se tratar de uma narrativa cuja história é contada por meio dos pensamentos da narradora, "A velocidade da narrativa definir-se-á pela relação entre uma duração, a da história, medida em segundos, minutos, horas, dias, meses e anos, e uma extensão: a do texto, medida em linhas e em páginas" (GENETTE, 1979, p. 123). Tudo o que é contado se passa em um espaço de tempo muito pequeno, no entanto, a engenhosidade da escrita, por meio das memórias, torna o texto rápido em suas ações sem deixar de narrar a vida completa da personagem central, Remigia. Tão rápido é que a própria narradora revela: "Yo no sé cómo despedirme"13 (PLÁ, 1996, p. 213), em sua última fala do texto.

\footnotetext{
${ }^{12}$ Tradução nossa: "Eu quero ir para minha casa. Somente lá vou me curar. Sempre adoecia e me curava sozinha."

${ }^{13}$ Tradução nossa: "Eu não sei como despedir-me."
} 


\section{Palavras finais}

Em se tratando de análise e interpretação de uma obra literária, que é o objetivo de boa parte das pesquisas dos estudos de literatura, a questão de seus limites tem-se mostrado por demasiado dificultosa, bem como na teoria literária. "Não se pode fazer uma obra significar qualquer coisa: ela resiste e você tem de se esforçar para convencer os outros da pertinência de sua leitura." (CULLER, 1999, p. 68). Confirmando a ideia de Culler, acreditamos que pertinência é a palavra-chave para os estudos literários, não importando se a análise/interpretação é mitigada ou extremada. E é essa pertinência, essa atribuição pertinente de valor que buscamos ao ler, nesta pesquisa a obra de Josefina Plá, uma leitura que não soe como uma discrepância entre obra e teoria.

Uma vez que a análise/interpretação de uma obra literária gira em torno do sentido, faz-se adequada a observção de Culler (1999):

O sentido de uma obra não é o que o autor tinha em mente em algum momento, tampouco é simplesmente uma propriedade do texto ou a experiência de um leitor. O sentido é uma noção inescapável porque não é algo simples ou simplesmente determinado. É simultaneamente uma experiência de um sujeito e uma propriedade de um texto. É tanto aquilo que compreendemos quanto aquilo que, no texto, tentamos compreender. Discussões sobre o sentido são sempre possíveis e, sendo assim, o sentido é impreciso, está sempre a ser decidido, sujeito a decisões que nunca são irrevogáveis. Se devemos adotar algum princípio ou fórmula geral, poderíamos dizer que o sentido é determinado pelo contexto, já que o contexto inclui regras de linguagem, a situação do autor e do leitor e qualquer outra coisa que poderia ser concebivelmente relevante. Mas, se dizemos que o sentido está preso ao contexto, então devemos acrescentar que o contexto é ilimitado: não se pode determinar de antemão o que poderia contar como relevante, que a ampliação do contexto poderia conseguir alterar o que consideramos como o sentido de um texto. $O$ sentido está preso ao contexto, mas o contexto é ilimitado. (1999, p. 70).

Logo o que temos que fazer é delimitar o contexto para que haja sentido no que escrevemos, pois "[...] não conhecemos o sentido de uma obra literária da mesma maneira que conhecemos o sentido de John is eager to please ${ }^{14}$ e, portanto, não podemos tomar o sentido como um dado mas temos que buscá-lo." (CULLER, 1999, p.65). Buscá-lo por meio de análises que sejam no mínino coerentes.

Posto que o sentido é o que buscamos em uma obra literária, temos então o sentido da obra aqui analisada, o conto Ña Remigia, pertencente à La Pierna de Severina,

\footnotetext{
${ }^{14}$ Tradução nossa: "John está ansioso por agradar".
} 
de Josefina Plá. Procuramos desenvolver uma análise que partisse necessariamente da estruturação do texto literário, buscando, assim, permear nossas análises com seus componentes mais elementares, os quais muitas pesquisas deixam totalmente de lado, as microestruturas textuais tempo, espaço e personagem. A partir delas, que são as formadoras do texto literário, é que trouxemos à tona as questões que permeiam o feminino, dentro de um contexto violento e trágico, e que convergem para o vazio e a solidão da personagem de Plá.

Não há como negar que a violência, das mais diversas miradas que se possa ter, nasce como constituição do homem e de sua cultura. Ela é tida como um membro fundador a partir do qual a própria sociedade se organiza e, como implicação disso, a criação humana e a expressão simbólica também o são. Assim, a história a adapta em temas literários a partir dos quais surgem obras que comportam uma violência de múltiplas nuanças, que pode ser encontrada desde os primórdios do que chamamos literatura.

\section{BIBLIOGRAFIA}

ARENDT, Hannah. Sobre a violência. Trad. André Duarte. Rio de Janeiro: Civilização Brasileira, 2011.

ARISTÓTELES. Poética. Trad. Eudoro de Souza. São Paulo: Nova Cultural, 2000. (Coleção "Os Pensadores").

BACHELARD, Gaston. A poética do espaço. Trad. Antonio de Pádua Danesi. 2. ed. São Paulo: Martins Fontes, 2008. 
CANDIDO, Antonio. A personagem do romance. In: ; ROSENFELD, Anatol; PRADO; Décio de Almeida; GOMES, Paulo Emílio Salles. A personagem de ficção. 10. ed. São Paulo: Perspectiva, 2002.

CASTELLO BRANCO, Lúcia. A traição de Penélope. São Paulo: Anablume, 1994. . O que é escrita feminina?. São Paulo: Brasiliense, 1991. (Primeiros Passos).

CULLER, Jonathan. Teoria Literária: uma introdução. Trad. Sandra Vasconcelos, São Paulo: Beca Publicações Culturais, 1999.

FORSTER, Edward Morgan. Aspectos do romance. Trad. Sergio Alcides. 4. ed. revisada. São Paulo: Globo, 2004.

HAMBURGER, Käte. A Lógica da Criação Literária. Trad. Margot P. Malnic. 2. ed. São Paulo: Perspectiva, 1986.

LACAN, Jacques. Estou falando com as paredes. Trad. Vera Ribeiro. Rio de Janeiro: Zahar, 2011.

LAJOLO, Marisa. Literatura: leitores e leitura. São Paulo: Ática, 2001.

LEITE, Ligia Chiappini Moraes. O foco narrativo. São Paulo: Ática, 1994. (Série Princípios).

MANNONI, Maud. Elas não sabem o que dizem: Virginia Woolf, as mulheres e a psicanálise. Trad. Lucy Magalhães. Rio de Janeiro: Jorge Zahar Ed. 1999.

PLÁ, Josefina. Cuentos completos. Org. Miguel Ángel Fernández. Asunción, PY: Editorial El Lector, 1996-A.

. Poesias Completas. Org. Miguel Ángel Fernández. Asunción PY: Editorial El Lector, 1996-B.

SELIGMANN-SILVA, Márcio. O local da diferença: ensaios sobre memória, arte, literatura e tradução. São Paulo: Ed. 34, 2005.

SZONDI, Peter. Ensaio sobre o trágico. Trad. Pedro Süssekind. Rio de Janeiro: Jorge Zahar, 2004.

TADIÉ, Jean Yves. A crítica literária no século XX. Trad. Wilma Freitas Ronald de Carvalho. Rio de Janeiro: Bertrand Brasil, 1992. 